\title{
M/M/1 Multiple Vacation Queueing Systems with Differentiated Vacations
}

\author{
Oliver C. Ibe and Olubukola A. Isijola \\ Department of Electrical and Computer Engineering, University of Massachusetts, Lowell, 1 University Avenue, Lowell, MA 01854, USA \\ Correspondence should be addressed to Oliver C. Ibe; oliver_ibe@uml.edu
}

Received 12 March 2014; Revised 12 June 2014; Accepted 17 June 2014; Published 23 July 2014

Academic Editor: Tadashi Dohi

Copyright (C) 2014 O. C. Ibe and O. A. Isijola. This is an open access article distributed under the Creative Commons Attribution License, which permits unrestricted use, distribution, and reproduction in any medium, provided the original work is properly cited.

We consider a multiple vacation queueing system in which a vacation following a busy period has a different distribution from a vacation that is taken without serving at least one customer. For ease of analysis it is assumed that the service times are exponentially distributed and the two vacation types are also exponentially distributed but with different means. The steady-state solution is obtained.

\section{Introduction}

A vacation queueing system is one in which a server may become unavailable for a random period of time from a primary service center. The time away from the primary service center is called a vacation, and it can be the result of many factors. In some cases the vacation can be the result of server breakdown, which means that the system must be repaired and brought back to service. It can also be a deliberate action taken to utilize the server in a secondary service center when there are no customers present at the primary service center. Thus, server vacations are useful for those systems in which the server wishes to utilize his idle time for different purposes, and this makes the queueing model be applicable to a variety of real world stochastic service systems.

Queueing systems with server vacations have attracted the attention of many researchers since the idea was first discussed in the paper of Levy and Yechiali [1]. Several excellent surveys on these vacation models have been done by Doshi $[2,3]$, and the books by Takagi [4] and Tian and Zhang [5] are devoted to the subject.

There are different types of vacation queueing systems. In the single vacation scheme, the server takes a vacation of a random duration when the queue is empty. At the end of the vacation the server returns to the queue. If there is at least one customer waiting when the server returns from vacation, the server performs one of the following actions depending on the service policy.

(a) Under the exhaustive service policy, the server will serve all waiting customers as well as those that arrive while he is still serving at the station. He takes another vacation when the queue becomes empty.

(b) Under the gated service policy, the server will serve only those customers that he finds at the queue upon his return from vacation. At the end of their service the server will commence another vacation and any customers that arrive while the server was already serving at the station will be served when the server returns from the vacation.

(c) Under the limited service policy, the server will serve only a predefined maximum number of customers and then will commence another vacation. The singleservice scheme in which exactly one customer is served is a special type of this policy.

If the queue is empty on the server's return, the server waits to complete a busy period using one of the service policies before taking another vacation.

In the multiple vacation scheme, if the server returns from a vacation and finds the queue empty, he immediately 
commences another vacation. If there is at least one waiting customer, then he will commence service according to the prevailing service policy.

Observe that in the vacation queueing system we have described the server completely stops service or is switched off when he is on vacation. Recently, Servi and Finn [6] introduced the working vacation scheme, in which the server works at a different rate rather than completely stopping service during a vacation. They applied the $M / M / 1$ queue with multiple working vacations to model a WavelengthDivision Multiplexing optical access network and derived the probability-generating function (PGF) of the number of customers in the system. In the original formulation of the working vacation scheme the server cannot be interrupted when he is on vacation; he resumes full service only when his vacation ends.

The working vacation scheme has attracted a lot of research effort, and several authors have extended the original model. Wu and Takagi [7] generalized the model in [6] to an $\mathrm{M} / \mathrm{G} / 1$ queue with general working vacations. Baba [8] studied a $\mathrm{GI} / \mathrm{M} / 1$ queue with working vacations by using the matrix analytic method. Banik et al. [9] analyzed the $\mathrm{GI} / \mathrm{M} / 1 / \mathrm{N}$ queue with working vacations. Liu et al. [10] established a stochastic decomposition result in the $\mathrm{M} / \mathrm{M} / 1$ queue with working vacations.

For the batch arrival queues, Xu et al. [11] studied a batch arrival $\mathrm{M}^{X} / \mathrm{M} / 1$ queue with single working vacation. Using the matrix analytic method, they derived the PGF of the stationary system length distribution. Baba [12] studied a batch arrival $\mathrm{M}^{X} / \mathrm{M} / 1$ queue with multiple working vacations. He obtained the PGF of the stationary system length distribution and the stochastic decomposition structure of system length that indicates the relationship with that of $\mathrm{M}^{X} / \mathrm{M} / 1$ queue without vacation.

Some researchers have also considered discrete-time working vacation systems. Tian et al. [13] considered the discrete time $\mathrm{Geo} / \mathrm{Geo} / 1$ queue with multiple working vacations. $\mathrm{Li}$ and Tian [14] analyzed the discrete-time Geo/Geo/1 queue with single working vacation. Gao and Liu [15] analyzed the performance of a discrete-time Geo ${ }^{X} / \mathrm{G} / 1$ queue with single working vacation. Li et al. [16] discussed a discrete-time batch arrival Geo ${ }^{X} / \mathrm{GI} / 1$ queue with working vacations.

Li and Tian [17] analyzed a GI/Geo/1 queue with working vacations and vacation interruption. Under such a policy, the server can come back to the normal working level before the vacation ends. They obtained the steady-state distributions for the number of customers in the system at arrival epochs and waiting time for an arbitrary customer using the matrixgeometric solution method. The authors also extended the model to the $M / M / 1$ queue with working vacation and vacation interruptions [18]. The GI/M/1 queue with working vacations and vacation interruption was studied by $\mathrm{Li}$ et al. [19]. Similarly, Zhang and Hou [20] discussed an M/G/1 queue with multiple working vacations and vacation interruption.

Recall that in the multiple vacation queueing system it is assumed that the vacation times are independent and identically distributed. However, there are practical environments where this assumption may not be valid. Specifically, a vacation taken after "a hard day's work" during which many customers have been served may be longer than a vacation taken after the server returns from vacation and finds the queue empty. We define a vacation queueing system that distinguishes between two kinds of vacations that a server can take as a vacation queueing system with differentiated vacations. The analysis of the $\mathrm{M} / \mathrm{M} / 1$ version of this type of vacation queueing system is the subject of this paper.

Thus, the paper deals with an $\mathrm{M} / \mathrm{M} / 1$ queueing system in which two types of vacations can be taken by the server: a vacation taken immediately after the server has finished serving at least one customer and a vacation taken immediately after the server has just returned from a previous vacation to find that there are no customers waiting.

The model is motivated by certain aspects of human and physical system behavior. For example, a computer system can suffer one of two types of failures: permanent failure and intermittent failure [21]. A permanent failure, which is sometimes called a hard failure, requires the physical repair of the failed system, which usually takes a long time because it requires the presence of the field services personnel. By contrast, after a system has suffered an intermittent failure (or soft failure), no physical repair is required. The system is restored to operation by means of a system reboot or some other repair function that does not require the presence of the field services personnel. As long as the system is not being used for the intended service, it can be modeled as being on vacation. Thus, vacations associated with intermittent failures are generally of shorter durations than vacations associated with permanent failures.

Another example is the following. Consider a gas station attendant who operates under the following policy. When there is no customer waiting to be attended he will take a break that he can use to perform other functions at the station. At the end of the break if there is still no waiting customer, he will take another break, but if there is at least one waiting customer, he will serve exhaustively and will take a break when all customers have been served. This is the traditional multiple vacation model. Suppose now that there are two types of breaks that he can take. Specifically, after serving all customers in a busy period that includes at least one customer, he will take a coffee break or a personal break whose length has a given distribution. If he returns from a break and there is no waiting customer, he goes back on another break whose length has another distribution. This time can be used to attend to other duties at the station and usually has a shorter mean duration than the coffee/personal break. Thus, long breaks are associated with the completion of a busy period with at least one service completion while short breaks are associated with busy periods of zero length.

In general, differentiated vacations occur in environments where "breaks" of different durations can occur. In this paper we have associated these breaks with the durations of busy periods.

Note that this model is different from the traditional multiple vacation model because in the traditional multiple vacation model the durations of vacations are identically distributed and are independent of the number of customers 


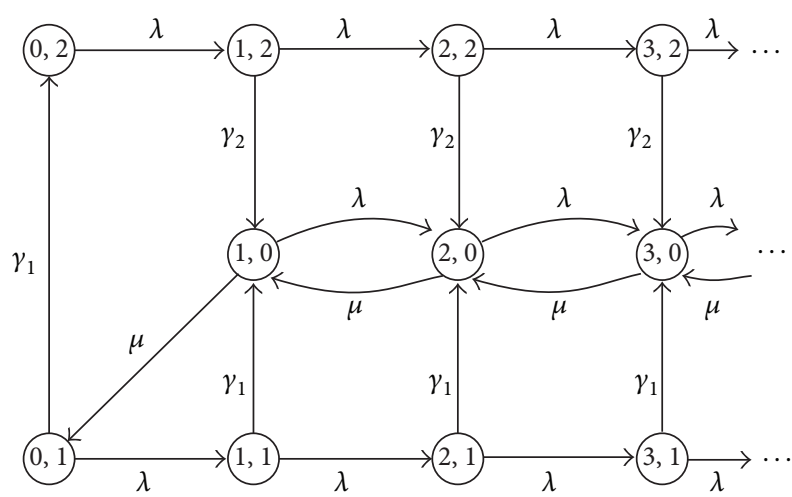

FIGURE 1: State-transition-rate diagram.

served in the busy period preceding the vacation. In the differentiated vacation model that we are proposing, there are two distributions of the durations of vacations: one is associated with a vacation taken after a nonzero busy period and the other is associated with a vacation taken after a zero busy period. The practical application of this model is that durations of vacations taken after a nonzero busy period can be longer than those that are taken when the server did not serve any customer prior to the vacation in order to give the server a sufficient time to rest following some hectic busy period.

The paper is organized as follows. The model is more formally defined in Section 2. Steady-state analysis of the model is given in Section 3, computational results are given in Section 4, and concluding remarks are made in Section 5.

\section{System Model}

We consider a multiple vacation queueing system where customers arrive according to a Poisson process with rate $\lambda$. The time to serve a customer is assumed to be exponentially distributed with mean $1 / \mu$, where $\mu>\lambda$. We assume that there are two types of vacations: type 1 vacation that is taken after a busy period of nonzero duration, and type 2 vacation that is taken when no customers are waiting for the server when it returns from a vacation. For ease of analysis we assume that the durations of type 1 vacations are independent of the busy period and are exponentially distributed with mean $1 / \gamma_{1}$. (As discussed earlier, there are cases where this independence assumption is not valid. However, we make this assumption to simplify the analysis.) Similarly, durations of type 2 vacations are assumed to be exponentially distributed with mean $1 / \gamma_{2}$.

Let the state of the system be denoted by $(r, k)$, where $r$ is the number of customers in the system, $k=0$ if the server is active serving customers, $k=1$ if the server is on a type 1 vacation, and $k=2$ if the server is on a type 2 vacation. Thus, the system can be modeled by a continuoustime Markov chain whose state-transition-rate diagram is shown in Figure 1.

\section{Steady-State Analysis}

Let $p_{n, k}(t)$ denote the probability that the process is in state $(n, k)$ at time $t$, and let

$$
p_{n, k}=\lim _{t \rightarrow \infty} p_{n, k}(t) .
$$

The main result of the paper is stated via the following theorem.

Theorem 1. The steady-state probability $p_{n, k}$ is given by

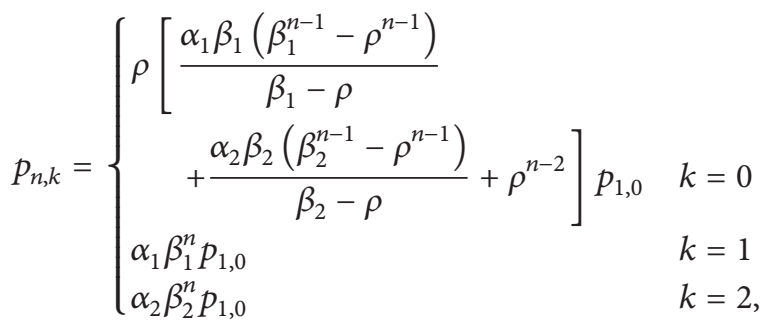

where

$$
\begin{aligned}
p_{1,0}= & \left((1-\rho)\left(1-\beta_{1}\right)\left(1-\beta_{2}\right)\right) \\
\times & \left(\left(1-\beta_{1}\right)\left(1-\beta_{2}\right)+\alpha_{1}\left(1-\beta_{2}\right)\right. \\
& \times\left\{1-\rho\left(1-\beta_{1}\right)\right\}+\alpha_{2}\left(1-\beta_{1}\right) \\
& \left.\times\left\{1-\rho\left(1-\beta_{2}\right)\right\}\right)^{-1},
\end{aligned}
$$

$\rho=\lambda / \mu$ is the offered load, $\alpha_{1}=\mu /\left(\lambda+\gamma_{1}\right), \alpha_{2}=\mu \gamma_{1} / \lambda\left(\lambda+\gamma_{1}\right)$, $\beta_{1}=\lambda /\left(\lambda+\gamma_{1}\right)<1$, and $\beta_{2}=\lambda /\left(\lambda+\gamma_{2}\right)<1$.

Proof. From global balance we have that

$$
\left(\lambda+\gamma_{1}\right) p_{0,1}=\mu p_{1,0} .
$$

Thus,

$$
p_{0,1}=\frac{\mu}{\lambda+\gamma_{1}} p_{1,0}=\alpha_{1} p_{1,0}
$$

where $\alpha_{1}=\mu /\left(\lambda+\gamma_{1}\right)$. Similarly,

$$
\lambda p_{0,2}=\gamma_{1} p_{0,1},
$$

which gives

$$
p_{0,2}=\frac{\gamma_{1}}{\lambda} p_{0,1}=\left(\frac{\gamma_{1}}{\lambda}\right)\left(\frac{\mu}{\lambda+\gamma_{1}}\right) p_{1,0}=\alpha_{2} p_{1,0},
$$

where $\alpha_{2}=\mu \gamma_{1} / \lambda\left(\lambda+\gamma_{1}\right)$. Also, for $n=0,1,2, \ldots$, we have that

$$
\begin{aligned}
& \lambda p_{n, 1}=\left(\lambda+\gamma_{1}\right) p_{n+1,1}, \\
& \lambda p_{n, 2}=\left(\lambda+\gamma_{2}\right) p_{n+1,2},
\end{aligned}
$$

which implies that

$$
\begin{aligned}
& p_{n+1,1}=\frac{\lambda}{\lambda+\gamma_{1}} p_{n, 1} \quad n=0,1,2, \ldots, \\
& p_{n+1,2}=\frac{\lambda}{\lambda+\gamma_{2}} p_{n, 2} \quad n=0,1,2, \ldots .
\end{aligned}
$$


Solving the above equations recursively we obtain

$$
\begin{aligned}
p_{n, 1} & =\left(\frac{\lambda}{\lambda+\gamma_{1}}\right)^{n} p_{0,1}=\alpha_{1}\left(\frac{\lambda}{\lambda+\gamma_{1}}\right)^{n} p_{1,0} \\
& =\alpha_{1} \beta_{1}^{n} p_{1,0} \quad n=0,1,2, \ldots, \\
p_{n, 2} & =\left(\frac{\lambda}{\lambda+\gamma_{2}}\right)^{n} p_{0,2}=\alpha_{2}\left(\frac{\lambda}{\lambda+\gamma_{2}}\right)^{n} p_{1,0} \\
& =\alpha_{2} \beta_{2}^{n} p_{1,0} \quad n=0,1,2, \ldots,
\end{aligned}
$$

where $\beta_{1}=\lambda /\left(\lambda+\gamma_{1}\right)<1$ and $\beta_{2}=\lambda /\left(\lambda+\gamma_{2}\right)<1$. From local balance we obtain

$$
\lambda p_{n, 0}+\lambda p_{n, 1}+\lambda p_{n, 2}=\mu p_{n+1,0} \quad n=1,2, \ldots
$$

If we define $\rho=\lambda / \mu$, then for $n=1,2, \ldots$, we obtain

$$
\begin{aligned}
p_{n+1,0} & =\rho p_{n, 0}+\rho p_{n, 1}+\rho p_{n, 2} \\
& =\rho p_{n, 0}+\rho \alpha_{1} \beta_{1}^{n} p_{1,0}+\rho \alpha_{2} \beta_{2}^{n} p_{1,0} .
\end{aligned}
$$

Solving recursively we obtain

$$
\begin{aligned}
p_{2,0}= & \rho\left\{\alpha_{1} \beta_{1}+\alpha_{2} \beta_{2}+1\right\} p_{1,0} \\
= & \rho\left\{\frac{\alpha_{1} \beta_{1}\left(\beta_{1}-\rho\right)}{\beta_{1}-\rho}+\frac{\alpha_{2} \beta_{2}\left(\beta_{2}-\rho\right)}{\beta_{2}-\rho}+\rho^{0}\right\} p_{1,0}, \\
p_{3,0}= & \rho\left\{\alpha_{1} \beta_{1}^{2}+\alpha_{2} \beta_{2}^{2}+\rho \alpha_{1} \beta_{1}+\rho \alpha_{2} \beta_{2}+\rho\right\} p_{1,0} \\
= & \rho\left\{\frac{\alpha_{1} \beta_{1}\left(\beta_{1}^{2}-\rho^{2}\right)}{\beta_{1}-\rho}+\frac{\alpha_{2} \beta_{2}\left(\beta_{2}^{2}-\rho^{2}\right)}{\beta_{2}-\rho}+\rho\right\} p_{1,0}, \\
p_{4,0}= & \rho\left\{\alpha_{1} \beta_{1}^{3}+\alpha_{2} \beta_{2}^{3}+\rho \alpha_{1} \beta_{1}^{2}+\rho \alpha_{2} \beta_{2}^{2}\right. \\
& \left.+\rho^{2} \alpha_{1} \beta_{1}+\rho^{2} \alpha_{2} \beta_{2}+\rho^{2}\right\} p_{1,0} \\
= & \rho\left\{\frac{\alpha_{1} \beta_{1}\left(\beta_{1}^{3}-\rho^{3}\right)}{\beta_{1}-\rho}+\frac{\alpha_{2} \beta_{2}\left(\beta_{2}^{3}-\rho^{3}\right)}{\beta_{2}-\rho}+\rho^{2}\right\} p_{1,0} .
\end{aligned}
$$

Thus, in general we obtain

$$
\begin{gathered}
p_{n, 0}=\rho\left\{\frac{\alpha_{1} \beta_{1}\left(\beta_{1}^{n-1}-\rho^{n-1}\right)}{\beta_{1}-\rho}+\frac{\alpha_{2} \beta_{2}\left(\beta_{2}^{n-1}-\rho^{n-1}\right)}{\beta_{2}-\rho}\right. \\
\left.+\rho^{n-2}\right\} p_{1,0} \quad n=1,2, \ldots
\end{gathered}
$$

From the law of total probability, we have that

$$
\begin{aligned}
1=\sum_{n=1}^{\infty} p_{n, 0}+\sum_{n=0}^{\infty} p_{n, 1}+\sum_{n=0}^{\infty} p_{n, 2} \\
=p_{1,0}\left\{\frac{\alpha_{1}}{1-\beta_{1}}+\frac{\alpha_{2}}{1-\beta_{2}}+\frac{\alpha_{1} \beta_{1} \rho}{(1-\rho)\left(1-\beta_{1}\right)}\right. \\
\left.\quad+\frac{\alpha_{2} \beta_{2} \rho}{(1-\rho)\left(1-\beta_{2}\right)}+\frac{1}{1-\rho}\right\} \\
=p_{1,0}\left\{\left(\left(1-\beta_{1}\right)\left(1-\beta_{2}\right)+\alpha_{1}\left(1-\beta_{2}\right)\left\{1-\rho\left(1-\beta_{1}\right)\right\}\right.\right. \\
\left.\quad+\alpha_{2}\left(1-\beta_{1}\right)\left\{1-\rho\left(1-\beta_{2}\right)\right\}\right) \\
\left.\quad \times\left((1-\rho)\left(1-\beta_{1}\right)\left(1-\beta_{2}\right)\right)^{-1}\right\} .
\end{aligned}
$$

Thus, we obtain

$$
\begin{aligned}
p_{1,0}= & \left((1-\rho)\left(1-\beta_{1}\right)\left(1-\beta_{2}\right)\right) \\
\times & \left(\left(1-\beta_{1}\right)\left(1-\beta_{2}\right)+\alpha_{1}\left(1-\beta_{2}\right)\right. \\
& \times\left\{1-\rho\left(1-\beta_{1}\right)\right\}+\alpha_{2}\left(1-\beta_{1}\right) \\
& \left.\times\left\{1-\rho\left(1-\beta_{2}\right)\right\}\right)^{-1},
\end{aligned}
$$

which completes the proof.

The mean number of customers in the system is given by

$$
\begin{aligned}
E[N]= & \sum_{n=1}^{\infty} n p_{n, 0}+\sum_{n=0}^{\infty} n p_{n, 1}+\sum_{n=0}^{\infty} n p_{n, 2} \\
= & \left\{\frac{\alpha_{1} \beta_{1} \rho\left(2-\rho-\beta_{1}\right)}{(1-\rho)^{2}\left(1-\beta_{1}\right)^{2}}+\frac{\alpha_{2} \beta_{2} \rho\left(2-\rho-\beta_{2}\right)}{(1-\rho)^{2}\left(1-\beta_{2}\right)^{2}}\right. \\
& \left.+\frac{1}{(1-\rho)^{2}}+\frac{\alpha_{1} \beta_{1}}{\left(1-\beta_{1}\right)^{2}}+\frac{\alpha_{2} \beta_{2}}{\left(1-\beta_{2}\right)^{2}}\right\} p_{1,0} .
\end{aligned}
$$

Finally, from Little's formula [22] the mean time a customer spends in the system (or mean delay) is given by

$$
E[T]=\frac{E[N]}{\lambda} .
$$

\section{Computational Results}

We assume that $\mu=1$; thus, $\rho=\lambda$. This implies that

$$
\begin{aligned}
& \alpha_{1}=\frac{\mu}{\lambda+\gamma_{1}}=\frac{1}{\rho\left(1+\gamma_{1} / \rho\right)}=\frac{1}{\rho+\gamma_{1}}, \\
& \alpha_{2}=\left(\frac{\gamma_{1}}{\lambda}\right) \alpha_{1}=\frac{\gamma_{1}}{\rho^{2}\left(1+\gamma_{1} / \rho\right)}=\frac{\gamma_{1}}{\rho\left(\rho+\gamma_{1}\right)}, \\
& \beta_{1}=\frac{\lambda}{\lambda\left(1+\gamma_{1} / \lambda\right)}=\frac{1}{1+\gamma_{1} / \rho}=\frac{\rho}{\rho+\gamma_{1}}, \\
& \beta_{2}=\frac{\lambda}{\lambda\left(1+\gamma_{2} / \lambda\right)}=\frac{1}{1+\gamma_{2} / \rho}=\frac{\rho}{\rho+\gamma_{2}} .
\end{aligned}
$$




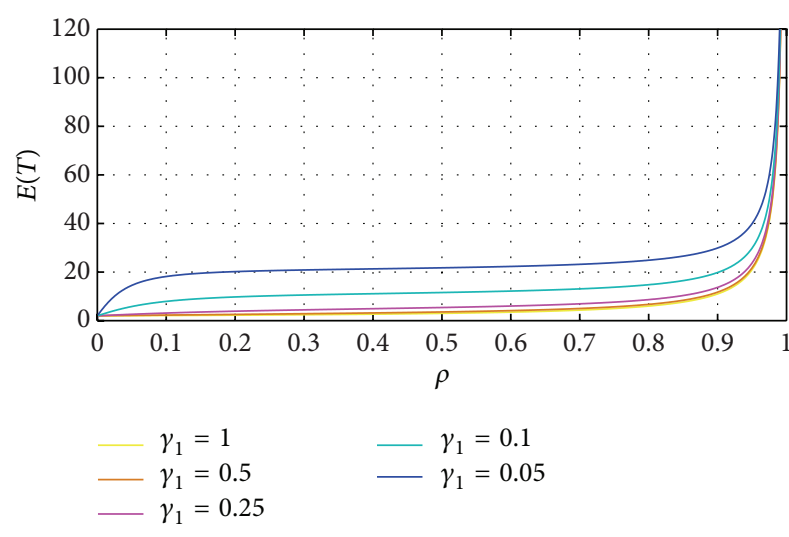

Figure 2: Mean time in system versus offered load for $\gamma_{2}=1$.

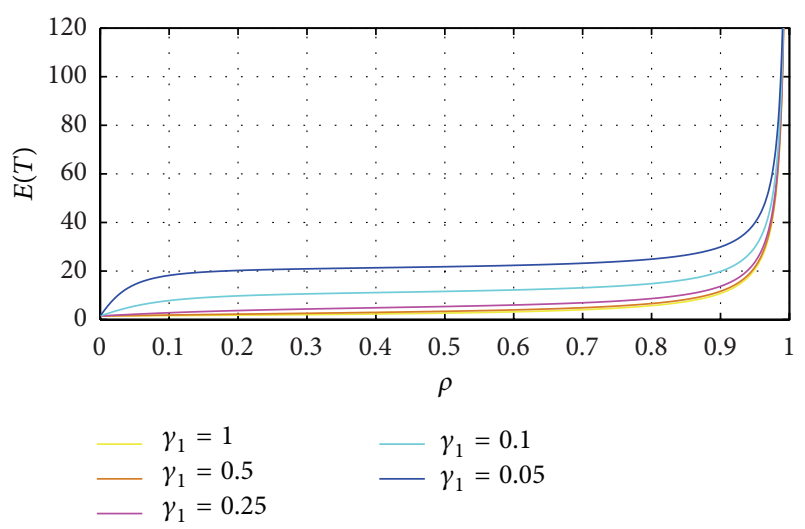

Figure 3: Mean time in system versus offered load for $\gamma_{2}=2$.

We also assume that the mean duration of type 1 vacation is at least as long as that of the type 2 duration, which means that $\gamma_{2} \geq \gamma_{1}$. We assume that $\gamma_{2}=1$ and consider different values of $\gamma_{1}: \gamma_{1}=1,0.5,0.25,0.1,0.05$. Figure 2 shows the variations of $E[T]$ with $\rho$. As the figure indicates, $E[T]$ increases as $1 / \gamma_{1}$ increases (corresponding to decreasing $\gamma_{1}$ ).

Figure 3 shows the results for $\gamma_{2}=2$ and $\gamma_{1}=1,0.5,0.25$, $0.1,0.05$. The figure shows the same trend observed in Figure 2.

\section{Conclusion}

We have considered an interesting class of multiple vacation queueing systems in which two types of vacations are encountered. The first type is a vacation that is taken at the end of a busy period of nonzero duration, and the second is a vacation taken at the end of a busy period of zero duration, which means that no customer was served. The simple case of $\mathrm{M} / \mathrm{M} / 1$ system is considered. The results indicate that the mean time a customer spends in the system, which we define as the mean delay, is more sensitive to the mean duration of the first type of vacation than of the second type, which is to be expected since the duration of the first type of vacation is assumed to be longer than that of the second type. This queueing system reflects many real life experiences where some vacations can be used for postprocessing activities while others are actual "breaks" that the server takes.

\section{Conflict of Interests}

The authors declare that there is no conflict of interests regarding the publication of this paper.

\section{Acknowledgments}

The authors wish to acknowledge the help of Nga Nguyen and Ogechi Ibe in producing the graphs in Figures 2 and 3. They also want to thank the reviewers for their comments on the application of the model to practical systems.

\section{References}

[1] Y. Levy and U. Yechiali, "Utilization of idle time in an $M / G / 1$ queueing system," Management Science, vol. 22, no. 2, pp. 202211, 1975.

[2] B. T. Doshi, "Queueing systems with vacations-a survey," Queueing Systems: Theory and Applications, vol. 1, no. 1, pp. 2966, 1986.

[3] B. Doshi, "Single server queues with vacations," in Stochastic Analysis of Computer and Communication Systems, H. Takag, Ed., pp. 217-265, Elsevier, 1990.

[4] H. Takagi, Queueing Analysis: A Foundation of Performance Analysis, vol. 1 of Vacation and Priority Systems, part 1, Elsevier Science Publishers B.V., Amsterdam, The Netherlands, 1991.

[5] N. Tian and Z. G. Zhang, Vacation Queueing Models: Theory and Applications, Springer, New York, NY, USA, 2006.

[6] L. D. Servi and S. G. Finn, "M/M/1 queues with working vacations (M/M/1/WV)," Performance Evaluation, vol. 50, no. 1, pp. 41-52, 2002.

[7] D. Wu and H. Takagi, "M/G/1 queue with multiple working vacations," Performance Evaluation, vol. 63, no. 7, pp. 654-681, 2006.

[8] Y. Baba, "Analysis of a GI/M/1 queue with multiple working vacations," Operations Research Letters, vol. 33, no. 2, pp. 201209, 2005.

[9] A. D. Banik, U. C. Gupta, and S. S. Pathak, "On the GI/M/1/N queue with multiple working vacations-analytic analysis and computation," Applied Mathematical Modelling, vol. 31, no. 9, pp. 1701-1710, 2007.

[10] W. Liu, X. Xu, and N. Tian, "Stochastic decompositions in the $M / M / 1$ queue with working vacations," Operations Research Letters, vol. 35, no. 5, pp. 595-600, 2007.

[11] X. Xu, Z. Zhang, and N. Tian, "Analysis for the $M^{X} / M / 1$ working vacation queue," International Journal of Information and Management Sciences, vol. 20, no. 3, pp. 379-394, 2009.

[12] Y. Baba, "The $\mathrm{M}^{X} / \mathrm{M} / 1$ queue with multiple working vacation," American Journal of Operations Research, vol. 2, no. 2, pp. 217224, 2012.

[13] N. Tian, Z. Ma, and M. Liu, "The discrete time Geom/Geom/1 queue with multiple working vacations," Applied Mathematical Modelling, vol. 32, no. 12, pp. 2941-2953, 2008.

[14] J. Li and N. Tian, "Analysis of the discrete time Geo/Geo/1 queue with single working vacation," Quality Technology \& Quantitative Management, vol. 5, no. 1, pp. 77-89, 2008. 
[15] S. Gao and Z. Liu, "Performance analysis of a discrete-time $\mathrm{Geo}^{\mathrm{X}} / \mathrm{G} / 1$ queue with single working vacation," World Academy of Science, Engineering and Technology, vol. 56, pp. 1162-1170, 2011.

[16] J. Li, W. Liu, and N. Tian, "Steady-state analysis of a discretetime batch arrival queue with working vacations," Performance Evaluation, vol. 67, no. 10, pp. 897-912, 2010.

[17] J. Li and N. Tian, "The discrete-time GI/Geo/1 queue with working vacations and vacation interruption," Applied Mathematics and Computation, vol. 185, no. 1, pp. 1-10, 2007.

[18] J. Li and N. Tian, "The M/M/1 queue with working vacations and vacation interruptions," Journal of Systems Science and Systems Engineering, vol. 16, no. 1, pp. 121-127, 2007.

[19] J. Li, N. Tian, and Z. Ma, "Performance analysis of GI/M/1 queue with working vacations and vacation interruption," Applied Mathematical Modelling, vol. 32, no. 12, pp. 2715-2730, 2008.

[20] M. Zhang and Z. Hou, "Performance analysis of M/G/1 queue with working vacations and vacation interruption," Journal of Computational and Applied Mathematics, vol. 234, no. 10, pp. 2977-2985, 2010.

[21] O. C. Ibe, R. C. Howe, and K. S. Trivedi, "Approximate availability analysis of VAXcluster systems," IEEE Transactions on Reliability, vol. 38, no. 1, pp. 146-152, 1989.

[22] J. D. C. Little, "A proof for the queuing formula: $L=\lambda W$," Operations Research, vol. 9, no. 3, pp. 383-387, 1961. 

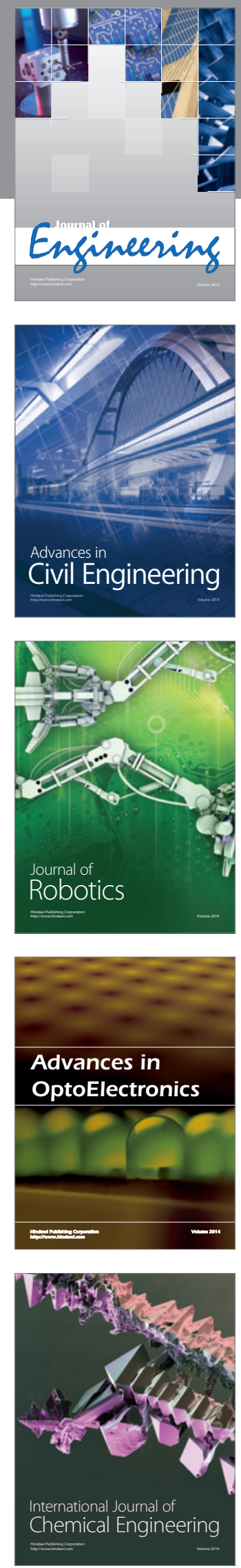

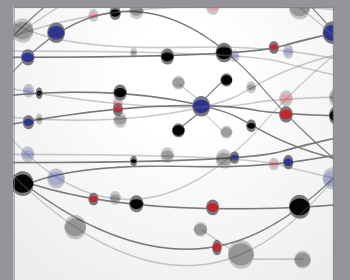

The Scientific World Journal
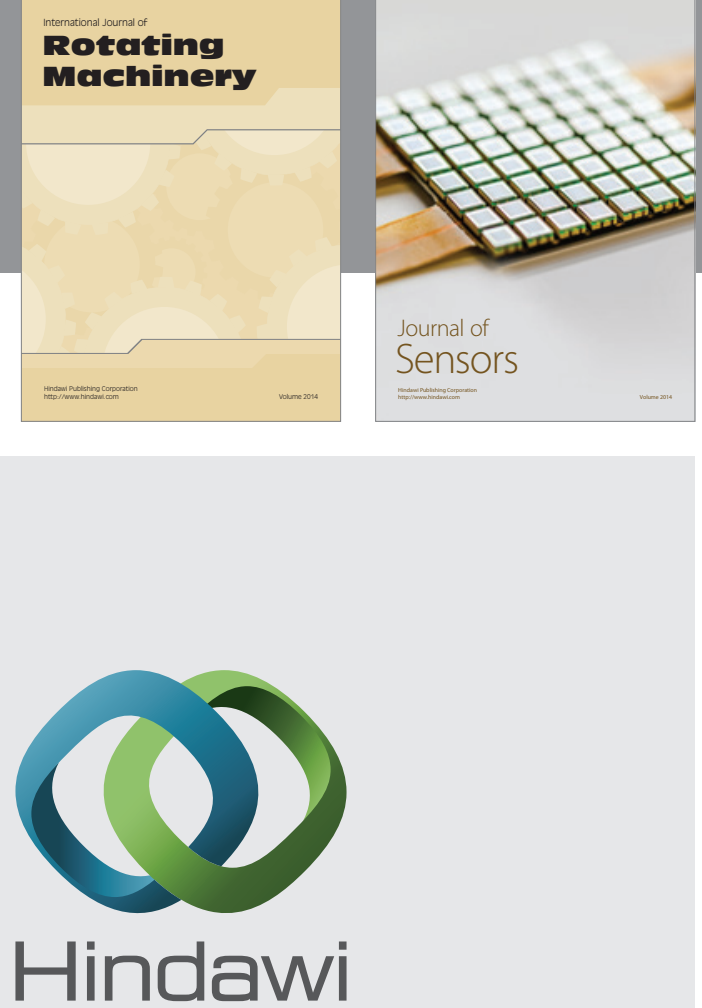

Submit your manuscripts at http://www.hindawi.com
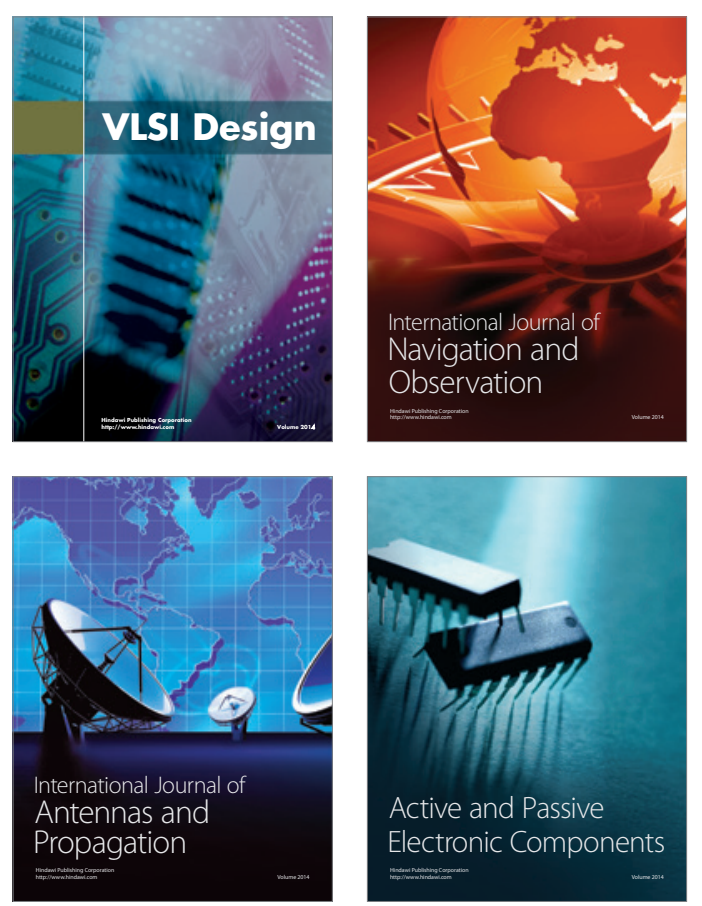
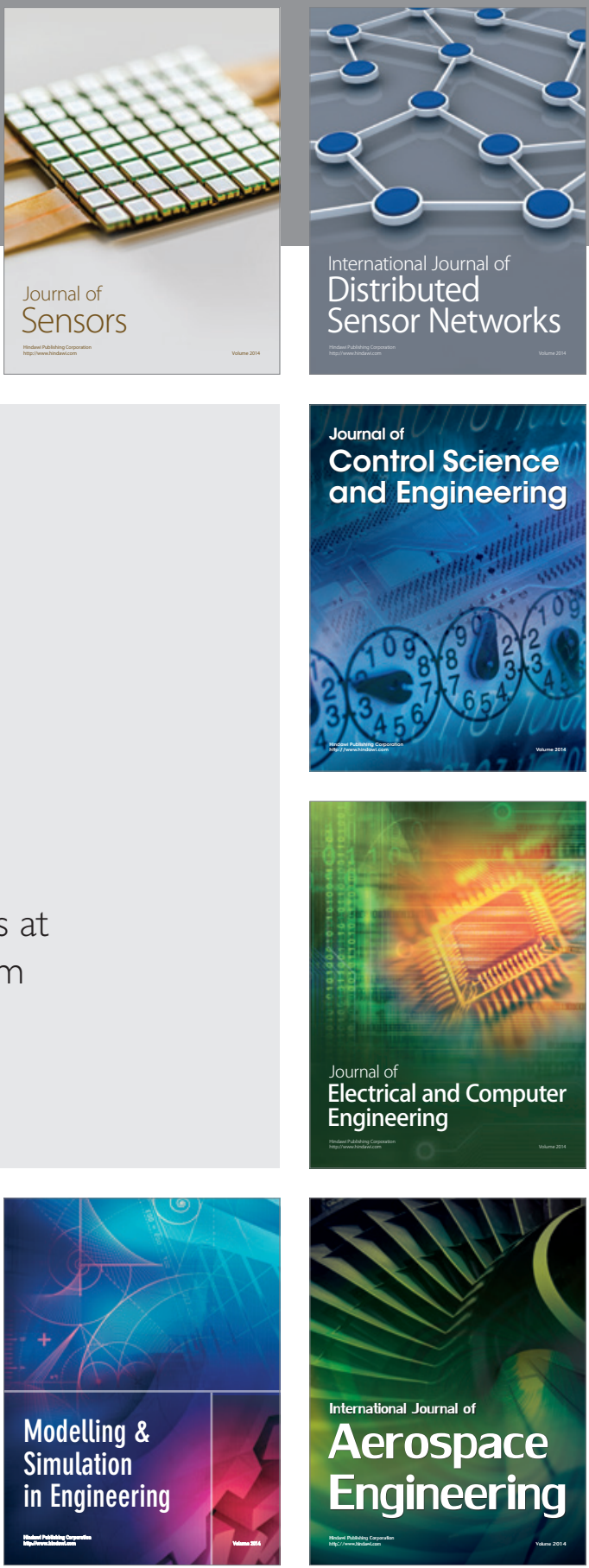

Journal of

Control Science

and Engineering
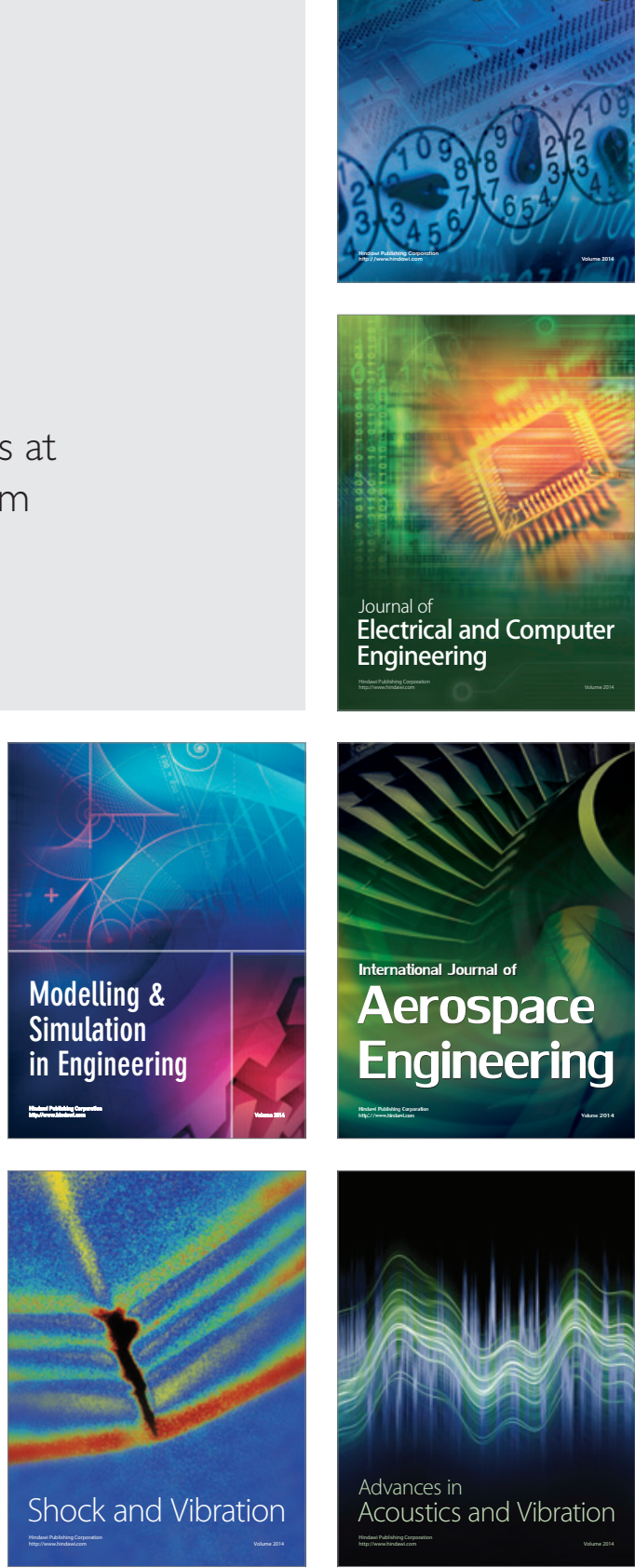